\title{
Diccionario de términos médicos de la Real Academia Nacional de Medicina: el sueño de un dermatólogo hecho por fin realidad
}

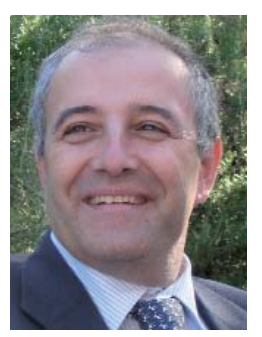

Fernando A. Navarro Especialista en lenguaje médico. Cabrerizos (Salamanca)
El pasado 27 de septiembre, se celebró en el salón de actos de la Real Academia Nacional de Medicina (RANM) el solemne acto de presentación del Diccionario de términos médi$\cos ^{1}$, presidido por José Manuel Blecua, director de la Real Academia Española, y Manuel Díaz-Rubio, presidente de la RANM.

En España y América, la clase médica ha prestado una calurosa acogida al que, después de muchos decenios, viene a ser el primer gran diccionario médico original pensado, elaborado y escrito directamente en español. Sus cifras, desde luego, son deslumbrantes: cerca de 52000 entradas, más de 66000 acepciones, casi 40000 remisiones internas, equivalentes en inglés para todos los términos definidos, información etimológica e histórica para cerca de siete mil tecnicismos médicos, definiciones actualizadas según los últimos conocimientos médicos, cerca de 35000 sinónimos y más de 27000 observaciones prácticas para resolver dudas en el uso de los términos y conceptos médicos.

Ahora que el nuevo diccionario anda en boca de todos, puede ser una ocasión excelente para recordar a quien fuera su impulsor: el dermatólogo Antonio García Pérez.

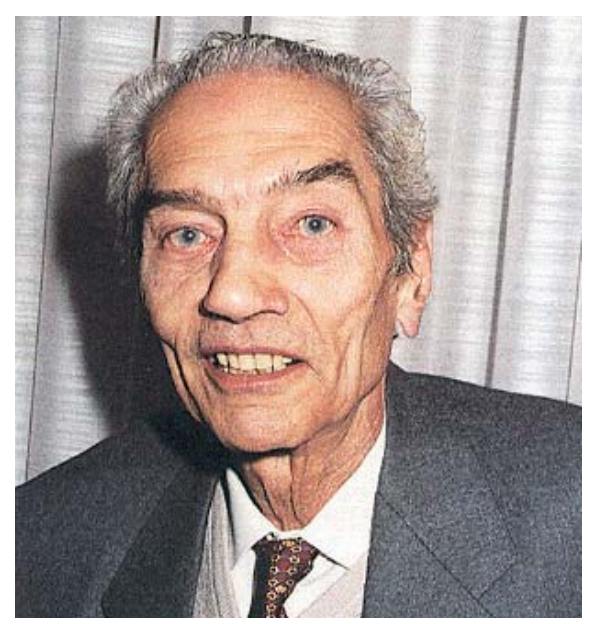

Antonio García Pérez (1923-2002)

Nunca tuve el gusto de saludarlo personalmente, pero sí mantuve con él una intensa relación epistolar desde agosto de 1996. Conocía de antes su figura profesional, desde luego: catedrático de Dermatología en Salamanca (1962-1975), Sevilla (19751980) y Madrid (hasta su jubilación en 1988); socio de la Academia Española de Dermatología y Venereología (AEDV) desde 1947, director de Actas Dermo-Sifiliográficas y presidente de la AEDV; socio fundador de la Academia Europea de Dermatología y Venereología (EADV, por sus siglas inglesas), vicepresidente del Colegio Ibero-Latinoamericano de Dermatología (CILAD), delegado en 
España de la Unión Europea de Médicos Especialistas (UEME), entre otros muchos cargos y distinciones. Pero como especialista en lenguaje médico, lo que más me llamó siempre la atención en García Pérez fue su destacado interés por el lenguaje de su especialidad, desde un capítulo que escribió en 1972 sobre la etimología del liquen² hasta un práctico diccionario bilingüe de dermatología ${ }^{3}$ cuya segunda edición, con cerca de 12000 entradas, llegó a las librerías pocos meses antes de su muerte.

No me extrañó en absoluto, por consiguiente, que García Pérez se mostrara como el dermatólogo más activo en los debates vinculados a la sección «Dermatología y lenguaje» que durante casi diez años mantuve, desde Basilea, en la revista Actas Dermo-Sifiliográficas. El lenguaje de la dermatología estuvo, pues, en el inicio de nuestra relación epistolar y de nuestra amistad.

La primera vez que oí hablar de un diccionario de la RANM fue precisamente en una carta suya mecanografiada - García Pérez no llegaría a utilizar nunca personalmente los ordenadores-y fechada en Madrid el 29 de septiembre de 1997, en la que me agradecía el envío de un ejemplar de cortesía de mi monografía Traducción y lenguaje en medicina (Barcelona: Fundación Esteve, 1987):

«Muchas gracias por su libro sobre Traducción y lenguaje, muy interesante y bien escrito. [...] Su libro me llega además en un momento oportuno. En la Real Academia de Medicina estamos tanteando el terreno para el ambicioso proyecto de preparar un Diccionario de terminología médi$c a$. En esta fase preinicial intentamos documentarnos sobre la técnica de preparación de diccionarios, a través de la Real Academia de la Lengua, y por otra parte, estamos haciendo una revisión crítica de otros diccionarios existentes, como el Dorland, el Roche, el Masson-Salvat, el Churchill, etc. Queremos también localizar bases de datos de terminología médica a través de Internet, tanto en castellano como en inglés, francés y alemán».
Casi dos años más tarde, en carta fechada el 26 de junio de 1999, me llegan nuevas noticias del proyecto:

«El diccionario sigue adelante, un poco al ralentí, y le dedico bastantes horas. Cuando nos veamos, le explicaré el método de trabajo y le pediré consejos, que desde luego me serán muy útiles. Las colaboraciones de casi la mayoría no son precisamente entusiastas, aunque algunos se han tomado la cosa más en serio y trabajan con actividad y eficacia. Pero entre preparar la informatización, que necesita un programa complejo, clasificar y repartir términos, etc., se puede decir que no hemos empezado hasta hace dos o tres meses».

¡Más de un año para empezar a definir las primeras palabras! Sí, en efecto, esos son los ritmos habituales en lexicografía de grandes proyectos. Diseñar una planta lexicográfica de novo, seleccionar el lemario, preparar plantillas de definición, organizar y capacitar un equipo de definidores..., todo ello lleva habitualmente más de un año para cualquier gran diccionario.

Y esa fase preparatoria no es más que el principio. Las verdaderas dificultades se presentan en cuanto uno empieza con las definiciones y comprueba que el proyecto puede prolongarse durante años. Se explica así que, a los pocos meses de entrar en la fase de definición del diccionario, García Pérez me escribiera el 28 de diciembre de 1999 en estos términos:

«[...] nuestro diccionario sigue su lento progresar. Estoy seguro de no verle impreso, pero creo que debemos gastarnos también en trabajos de este tipo».

Acertaba, sí, al expresar sus temores de no llegar a verlo impreso. García Pérez falleció el 31 de mayo del 2002, con el diccionario lejos, muy lejos aún de estar terminado. Todo hacía pensar que el proyecto de un diccionario especializado 
de medicina con el aval de la RANM caería una vez más en el olvido, como había venido siendo tristemente habitual en nuestra lexicografía (desde su creación en el siglo XVIII, de hecho, la RANM cuenta entre sus funciones la elaboración de un diccionario especializado). Refleja bien el sentir general tras la muerte de García Pérez este pasaje que reproduzco de una nota necrológica:

«En los últimos años, dirigía la elaboración de un nuevo diccionario en colaboración con la Real Academia Nacional de Medicina de España. Trabajaba en coordinación con los especialistas y buscaba personalmente las entradas. Creemos que, sin él, este proyecto nunca podría haberse puesto en marcha. Será difícil hallar a un sucesor con su misma experiencia y conocimientos léxicos, que tome el testigo y termine el diccionario» ${ }^{4}$.

Esa impresión tuvimos durante dos años, hasta que, en abril del 2004, la RANM anunció, en el marco del simposio «La terminología médica en los profesionales y en los medios de comunicación», que Hipólito Durán Sacristán había tomado oficialmente el relevo de García Pérez y que la Academia estaba firmemente decidida a llevar adelante el proyecto de un gran Diccionario de términos médicos de nueva planta. El resto, hasta ver hecho realidad en septiembre del 2011 el sueño del dermatólogo García Pérez, es ya historia, y puede leerse en otra parte ${ }^{5}$.

\section{BIBLIOGRAFÍA}

1 Real Academia Nacional de Medicina. Diccionario de términos médicos. Madrid: Panamericana; 2011. dtme.ranm.es

2 García Pérez A. Etimología del liquen. En: Temas dermatológicos. Madrid: Syntex; 1972.

3 Shapiro BL, García Pérez A. Diccionario dermatológico. Madrid: Ergon; 1995 [2.. edición, 2001].

4 Cruz A, Shapiro B. En el fallecimiento del profesor Antonio García Pérez (1923-2002). Panace@ 2002; 3: 111-2. medtrad.org/panacea.html

5 Navarro FA. Novedades en lexicografía médica (I): el Diccionario de términos médicos (2011) de la Real Academia Nacional de Medicina. Puntoycoma 2011; (123): 47-68. ec.europa.eu/ translation/bulletins/puntoycoma/numeros.html 